Portland State University

PDXScholar

1979

\title{
A study of the relationship between visual short term memory and speechreading in hearing impaired geriatrics
}

Catherine Hollevoet

Portland State University

Follow this and additional works at: https://pdxscholar.library.pdx.edu/open_access_etds

Part of the Psychology Commons, and the Speech Pathology and Audiology Commons Let us know how access to this document benefits you.

Recommended Citation

Hollevoet, Catherine, "A study of the relationship between visual short term memory and speechreading in hearing impaired geriatrics" (1979). Dissertations and Theses. Paper 2788.

https://doi.org/10.15760/etd.2783

This Thesis is brought to you for free and open access. It has been accepted for inclusion in Dissertations and Theses by an authorized administrator of PDXScholar. Please contact us if we can make this document more accessible: pdxscholar@pdx.edu. 
TO THE OFFICE OF GRADUATE STUDIES AND RESEARCH:

The members of the Committee approve the thesis of Catherine Hollevoet presented February $21,1979$.
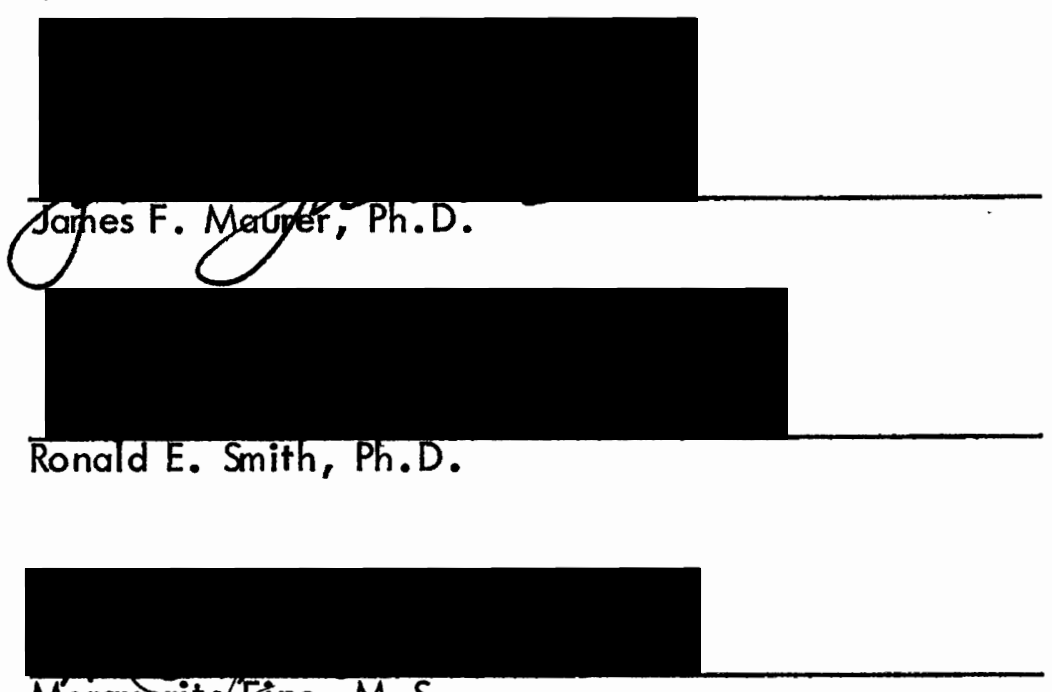

MargueritefFine, M.S.

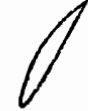

\section{APPROVED:}

Robert W. Vogel sang, Head, Defpartment of Speech Communication

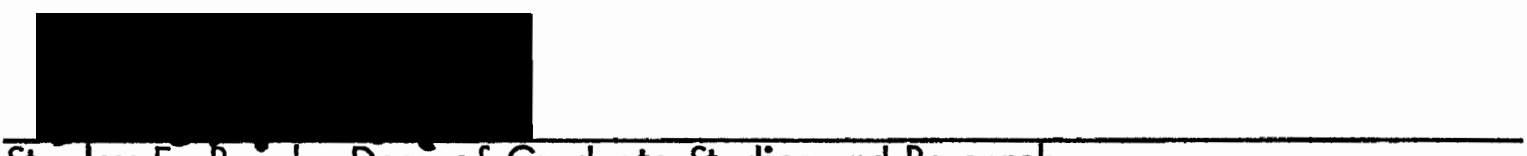

Stanley E. Rauch, Dean of Graduate Studies and Research 
AN ABSTRACT OF THE THESIS OF Catherine Hollevoet for the Master of Science in Speech Communication with major emphasis in Audiology and Speech Pathology presented February 21, 1979.

Title:

A Study of the Relationship Between Visual Short Term Memory and Speechreading in Hearing Impaired Geriatrics.

APPROVED BY MEMBERS OF THE THESIS COMMITTEE:

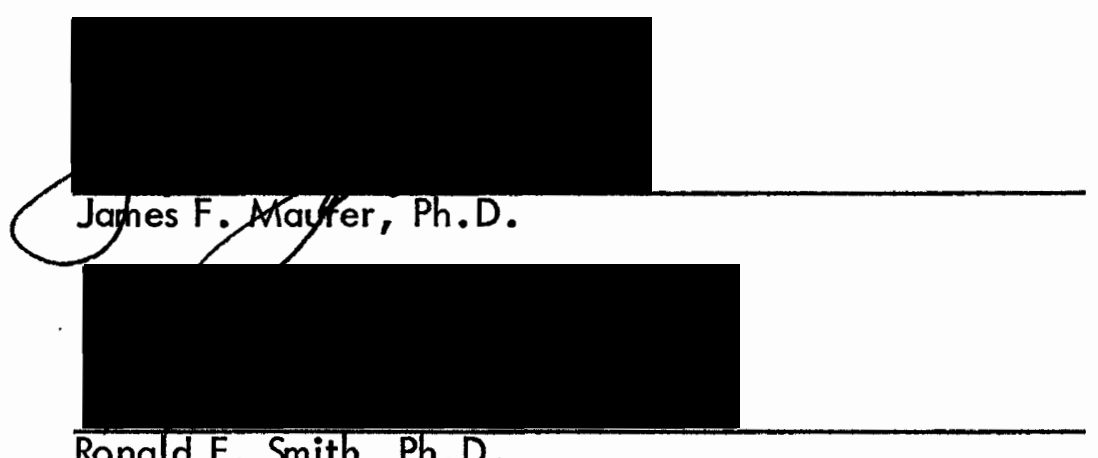

Ronald E. Smith, Ph.D.

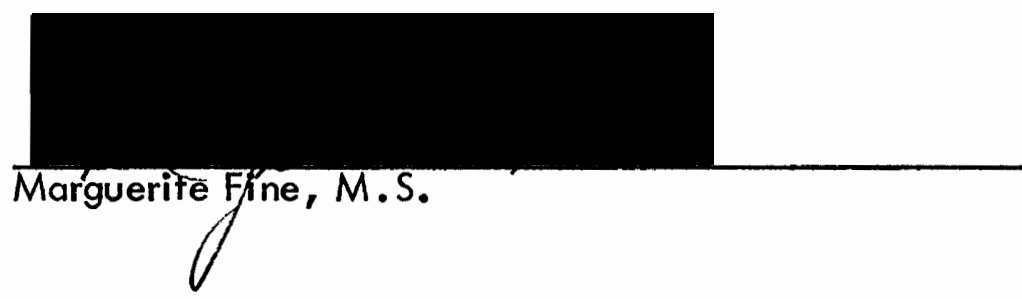

The relationship between visual short term memory (as measured by the Memory for Designs Test) and speechreading ability (as measured by the Barley Speechreading Test) was investigated in a sample of twenty-seven hearing impaired geriatrics. Correlation analysis verified a statistically significant relationship between Memory for Designs Test scores and Barley Speechreading Test scores. Partial 
correlation revealed the relationship between speechreading scores and short term memory scores was not influenced significantly by variance in chronological age or speech discrimination ability. Memory for Designs Test scores were shown to be accurate predictors of scores achieved on the Barley Speechreading Test.

Results of this study suggest that development of different approaches (for evaluating speechreading ability of geriatrics) could prove more informative and useful than the speechreading tests currently in use. For example, development of a speechreading test, composed of several subtests (such as visual short term memory) which would evaluate specific factors related to speechreading ability, would optimize both clinical time and client progress. 


\title{
A STUDY OF THE RELATIONSHIP
}

BETWEEN

VISUAL SHORT TERM MEMORY AND SPEECHREADING IN

HEARING IMPAIRED GERIATRICS

by

CATHERINE HOLLEVOET

A thesis submitted in partial fulfillment of the requirements for the degree of

\author{
MASTER OF SCIENCE \\ in \\ SPEECH COMMUNICATION \\ with emphasis in Audiology and Speech Pathology
}

Portland State University

1979 


\section{ACKNOWLEDGMENTS}

I wish to express my appreciation to:

Dr. James Maurer, my academic advisor, for his assistance and encouragement on this project as well as throughout my graduate studies.

Mrs. Marguerite Fine for providing her expertise on aural rehabilitation and for serving on my thesis committee.

Dr. Ronald Smith for serving on my thesis committee.

Alvin Black and my children, Orvis and Rick, for their constant support and confidence in my abilities. 
TABLE OF CONTENTS

PAGE

ACKNOWLEDGMENTS

LIST OF TABLES

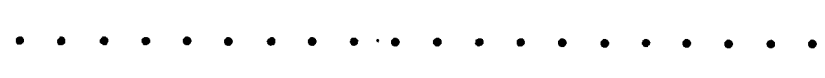

vi

LIST OF FIGURES

vii

CHAPTER

I INTRODUCTION ................... I

Statement of Purpose. ......... 3

II REVIEW OF THE LITERATURE . . . . . . . . . 5

Speechreading Defined. ......... 5

The Presbycusic and Speechreading. ...... 7

Visual Short Term Memory and Speechreading ... 12

Short Term Memory and Aging ........ 15

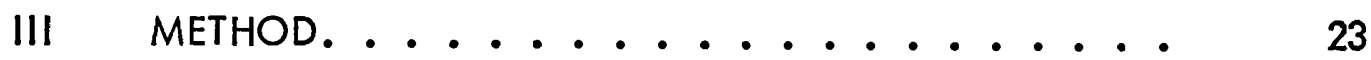

Subjects ............... 23

Instrumentation .................. 24

Procedures . . . . . . . . . . . 27

IV PRESENTATION OF RESULTS ............ 29

Discussion .................. 35 
CHAPTER

PAGE

V SUMMARY AND IMPLICATIONS ........

39

Implications for Future Research. .......

40

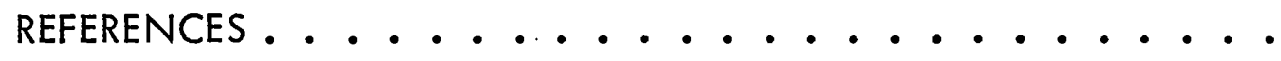

42 


\section{LIST OF TABLES}

TABLE

PAGE

1 Means of Raw Scores for Various Age Ranges of the 1960

Data and Over 60 Control Samples for the MFD ....

II Comparison of Data Obtained in this Study with Normative

Data Reported for the Barley Speechreading Test . . . .

III Comparison of Data Obtained in this Study with Normative

Data Reported for the Memory for Designs Test . . . . . 30

IV Comparison of Results from the Barley Speechreading Test and the Memory for Designs Test by Decades . . . . . . . .

V Original and Partial Correlations Between (1) Barley Speechreading scores, (2) Memory for Designs scores, (3) Age, and (4) Speech Discrimination scores .........

VI Percentage of Variance Found in Speechreading Attributed to Factors of Visual Short Term Memory, Age and Speech Discrimination Ability . . . . . . . . . .

VII Comparison of Soores Achieved by the Twenty-Seven Subjects on the Barley Speechreading Test with Predicted Soores . .

VIII Barley Speechreading Error Scores Achieved by Three Subjects compared to the Predicted Scores ........... 


\section{LIST OF FIGURES}

FIGURE

PAGE

1. Hearing Loss Due to Aging ..............

9

2. Iversen's Model of Memory ............... 17

3. Designs from Memory for Designs Test . . . . . . . . . 25 


\section{CHAPTER I}

\section{INTRODUCTION}

Speechreading has been utilized in the United States for well over one hundred years to supplement inadequate auditory functioning. During the early $1800^{\prime}$ s, speechreading was used as a method for teaching hearing impaired children to speak. Visual receptive language skills were thought to occur adventitiously as expressive language developed. It was not until the late 1800's and early 1900's that speechreading began to be recognized as a method for improving receptive communication in hearing handicapped adults (Deland, 1968). However, the methods remained essentially the same as those first used to teach speech to deaf children, i.e., a part to whole approach by teaching production of sounds.

Few clinicians involved in aural rehabilitation would disagree that there are distinct differences between the prelingually hearing handicapped child and the adult who experiences a gradual loss of hearing over a period of years. Yet the approaches and methods for teaching speechreading today do not appear to differ

significantly from those used at the tum of the century. While many severely hard-of-hearing children do become proficient speechreaders, there is a paucity of experimental evidence indicating success in speechreading with older hearing impaired adults using any of the known speechreading approaches. This may be due in part to the limited information available to the clinician regarding assess- 
ment and rehabilitation procedures for the older client.

Speechreading tests appropriate for adults are few and of questionable validity. Generally, a test is administered to assess an individual's level of proficien- . cy in a given area and to provide the clinician with a starting point from which to design a program for improving that skill. With such a program an individual's progress can be determined and compared with others similar in age and training. At this time, no standardized speechreading test has been developed. At best, the current speechreading tests permit the clinician to compare a score before intervention to a score obtained after some training. Whether or not the score is an indication of the persons ability to speechread in everyday communicative situations is not known. It is also difficult to ascertain if the materials used in teaching relate to the task presented by the speechreading test since personal experience has shown many people do poorer on the post-test than on the pretest.

In an attempt to remedy these problems, some investigators have turned to examining the factors which maybe important to the acquisition of speechreading. By viewing speechreading as a component skill made up of a number of elements, the clinician would be able to assess specific strengths and weaknesses. Teaching strategies could be developed and implemented to improve those areas which directly contribute to a person's overall ability to learn speechreading.

Jeffers and Barley (1971) have proposed a theoretical construct of possible factors contributing to speechreading acquisition. The primary factors are: (1) perceptual proficiency which included visual perception, speed of perception and 
peripheral perception; (2) synthetic ability which involved deriving meaning from fragments of the total message; and (3) flexibility to revise tentative closures resulting in a meaningful message. Within this framework, visual short term memory is considered ancillary to flexibility or revision of perceptual closures. Visual short term memory may be of greater importance to the older person's acquisition of good speechreading skill than is implied in this construct. Botwinick (1973) stated, "when differences in intellectual organization are found in people of different age, the differences tend to center around memory. In advanced age, much more than in earlier life, individual differences in memory ability account for the degree of success on a variety of tasks."

The relationship between speechreading and visual short term memory has not been investigated in the over sixty age group but short term memory has been shown to decline with age (Adamowicz, 1976; Botwinick, 1973; Craik, 1968; Taub, 1966). Knowledge of the relationship of visual short term memory to speechreading ability in older people could provide a starting point for development of individualized programs for teaching speechreading to this population.

\section{STATEMENT OF PURPOSE}

The purpose of this study was to determine if a significant relationship exists between visual short term memory and speechreading ability in older hearing impaired subjects.

The specific question posed was:

Do older hearing impaired subjects with good visual short term memory per- 
form better on a speechreading task than older hearing impaired subjects with poor visual short term memory? 


\section{CHAPTER II}

\section{REVIEW OF THE LITERATURE}

\section{SPEECHREADING DEFINED}

The terms "lipreading" and "speechreading" are generally used interchangeably to describe a process of perceiving speech through the visual channel. Lipreading connotes direct observation of lip movements to detect each phoneme produced by the speaker, a method used in the analytic teaching approach. Speechreading is a broader term meant to encompass the total process of receptive communication, via the visual channel, generally taught through a synthetic approach. These two terms have led to a proliferation of definitions. In the following discussion, the term speechreading will be used exclusively.

Nitchie (1930) described speechreading as "the art of understanding a speaker's thought by watching the movements of his mouth." Mason (1943) replaced the terms lipreading and speechreading with "visual hearing," a term she considered more accurate in delineating the processes involved. O'Neill and Oyer (1961) provided the expression "visual thought comprehension" to include the recognition of thoughts as well as units (phonemes and words) of language. They examined the similarities between auditory and visual reception of speech. Myklebust (1960) described speechreading as a process of receiving symbols by vision in much the 
same manner as hearing.

Others have compared the speechreading process to reading. Davis and Silverman (1960) described speechreading as learning to decode and holding in immediate memory a sequence of visual patterns and then comprehending that message according to the language code as in learning to read. Jeffers and Barley (1971) paraphrased a definition of reading, defining speechreading "as the gross process of looking at, perceiving and interpreting spoken symbols."

Analogous terms such as "visual hearing" and "visual communication" are meant to clarify the rather ambiguous term speechreading. However, the authors are quick to point out the differences between hearing or reading and the speechreading task. The speechreader cannot "visually hear" around corners, in the dark or at a distance to name only a few of the limitations. Unlike the reader, the speechreader cannot "review" what he missed but must recognize and decode a fleeting message. In addition, variables related to the sender and the message affect the speechreader's ability to perceive language through the visual channel (Berger, 1972; Jeffers and Barley, 1971; O'Neill and Oyer, 1961).

While most investigators acknowledge the shortcomings inherent in speechreading, it is still considered a valuable tool for the hearing impaired individual. As such, speechreading may be thought of as a method to be used for improving receptive communication ability when the sensory channel normally used for this purpose functions inadequately. It is not a method for teaching language; rather the task demands a knowledge of speech and language as a prerequisite to learning speechreading. Vernon and Mindel (1971) considered the major factor in speech- 
reading to be the "level of language development and not formal training." Since speechreading training is often an integral part of the total habilitation or rehabilitation program, it is assumed to be a form of learned behavior, learning being defined as a relatively permanent change in performance as a result of practice (Logan, 1970). O'Neill and Oyer (1961) stated, "if we do not accept [this] assumption..., we must assume that it [speechreading] is a trait." Studies which have shown improvement in speechreading following training include, Black et al. (1963) and Hutton (1960). Therefore, speechreading is defined as a learned behavior, composed of observing and interpreting spoken language for the purpose of improving communicative efficiency.

\section{THE PRESBYCUSIC AND SPEECHREADING}

Clinicians in charge of designing and implementing an aural rehabilitation program for the hearing impaired individual may become discouraged by seemingly insignificant gains in speechreading ability after months of practice. This is particularlytrue of the older hearing impaired adult. Studies which have attempted to isolate the factors contributing to the ability to learn speechreading have virtually ignored the over sixty person's specific strengths and weaknesses. There are a number of reasons for a closer examination of this population.

First, life expectancy has increased an additional twenty seven years since 1900 (Botwinick, 1973). Men, age sixty, have an average life expectancy of seventy-six and for women, the life expectancy is nearly five years longer (U.S. Bureau of the Census; 1976).. There are now over twenty million Americans aged 
sixty-five or older, an increase of eighteen percent since 1970. The number of senior citizens increases every year.

Second, a survey by Metropolitan Life (1976) reported the incidence of hearing loss among people ages sixty-five to seventy-four to average twenty three percent and this figure raises to forty percent for persons age seventy-five and older. The survey also found a thirty percent higher prevalence of hearing impairment among men than among women up to age seventy-five. This finding is attributed to a greater number of men being exposed to excessive noise during the working years. The difference decreases with increasing age. Goetzinger (1961) found the effect for sex nonsignificant when the hearing loss is attributed to age alone.

The final reason for examining the factors important to good speechreading skills among the older population, involves the nature of the hearing loss associated with advanced age. Audiometrically, the type of sensori-neural hearing loss due to aging, termed presbycusis, typically presents a bilateral, symmetrical configuration with the high frequenciesbeing affected first. The expected average and maximum pure tone hearing losses due to presbycusis, as determined by Hinchcliffe (1959), are shown in Figure 1 (British Standard Institution, B.S.2467, 1954 ). However, knowledge of the pure tone results does not provide adequate information for assessing the degree of the handicap the loss may present for the individual. The term presbycusis is used in a much broader sense to include a number of significant changes which can occur in the auditory systems of elderly people. Schuknecht (1964) suggested four main types of presbycusis. The first type, called sensory presbycusis, is characterized by a loss of sensory hair cells in the 


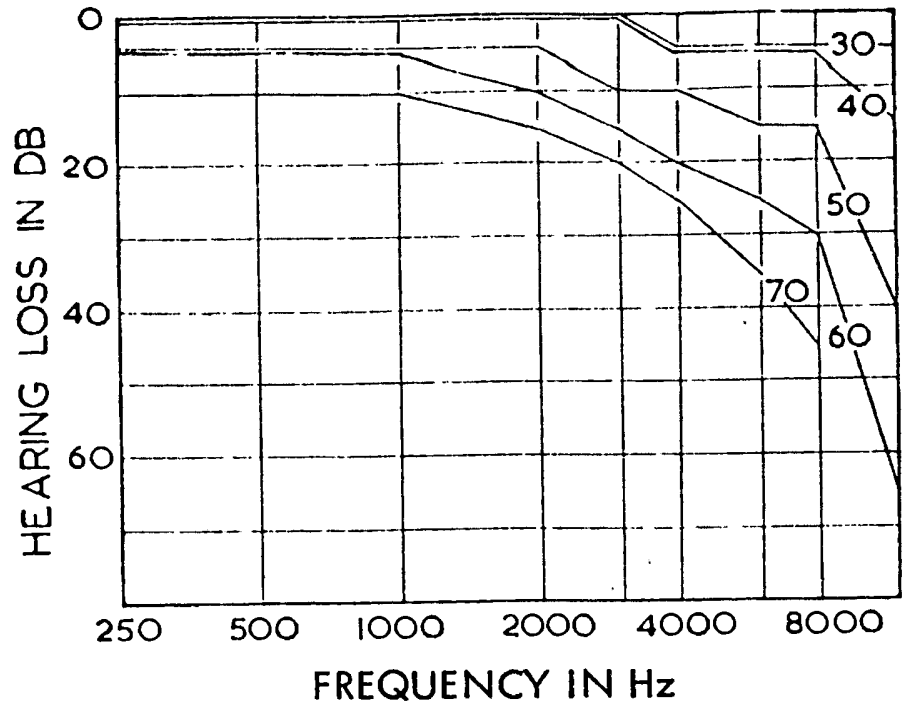

The curves indicate an average amount of hearing loss that might be expected to have occurred at given ages. The corresponding age in years is shown for each curve (from Hinchcliffe, 1959).

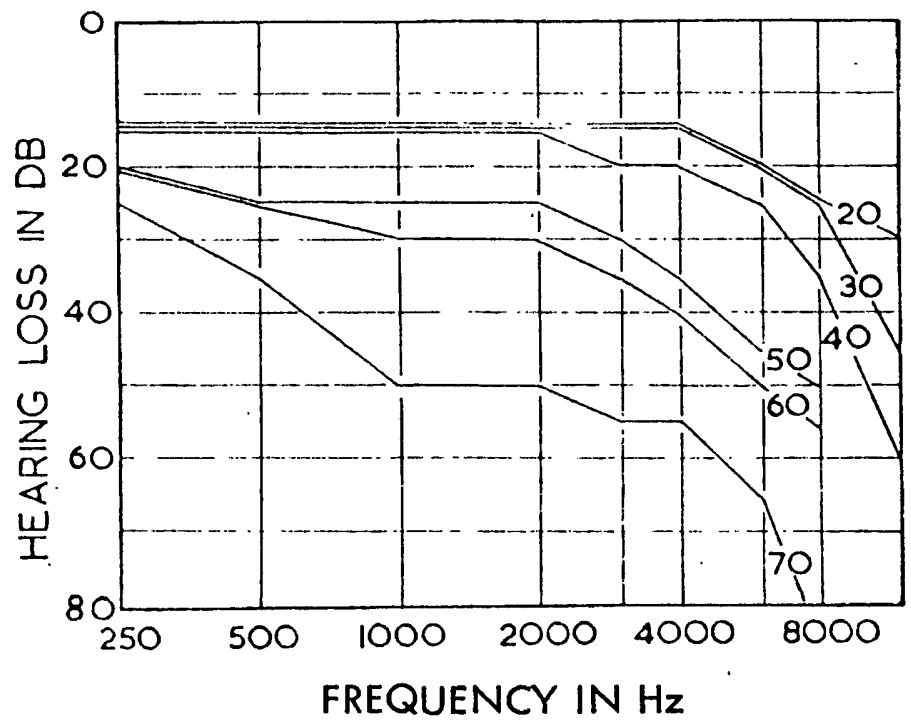

The curves indicate a probable maximum limit at each decade (from Hinchcliffe, 1959).

Figure 1. Hearing loss due to aging. 
basal end of the organ of Corti. This type of hearing loss results in reduced sensitivity for high frequency sounds and is represented in the typical pure tone audiogram obtained from the older person.

The second type, neural presbycusis, is due to a degeneration of neuron in the auditory pathways and cochlea. A number of investigators have attributed the finding of impaired speech discrimination, in excess of what would be expected from pure tone results, to this loss of neurons in the auditory system. Bocca (1958) found deficits in discrimination ability for distorted speech in older people to be indistinguishable from results obtained with younger people with temporal lobe damage. A study by Kirikae et al. (1964) reported similar results and attributed the lowered speech discrimination to reduction and atrophy of ganglion cells from the level of the spiral ganglion to the auditory cortex. Histological studies by Hansen and Reske-Nielson (1965) found greater degeneration in the white matter of the cerebral hemispheres than in the auditory pathways through the brain stem in a group of older hearing impaired patients.

A third type of presbycusis was termed metabolic, involving atrophy of the stria vascularis. This type of hearing loss generally presents a flat audiometric configuration with nearly equal threshold elevation at all frequencies. Johnsson and Hawkins (1972) referred to metabolic presbycusis as a special case of what they called vascular presbycusis distinguished by a loss of blood supply to the stria vascularis and tympanic lip.

A fourth type of presbycusis Schuknecht identified as mechanical. He hypothesized that this type of hearing loss occurs due to structural changes in the basilar 
membrane and presents a descending audiometric curve. An extensive study by Johnsson and Hawkins (1972) revealed atrophy and degeneration in structures of the organ of Corti and nerve fibers of older patients but found no evidence of morphological changes in the basilar membrane.

In addition to the changes in the inner ear and auditory pathways, Hinchcliffe (1962) noted structural changes in the external and middle ears of elderly patients. Glorig and Davis (1961) suggested a conductive component is present in presbycusis. While a mixed type of hearing loss may occur in some older individuals, a conductive element does not appear to be a consistent finding in presbycusis (Sataloff et al., 1965).

The research on hearing loss and aging illustrates the complexity of symptoms associated with the term presbycusis. Generally, the hearing loss is progressive and is not medically or surgically treatable. Of particular consequence to the older hearing impaired individual is the finding of excessive degradation in speech discrimination ability. The term "phonemic regression" was coined by Gaeth (1948) to describe this syndrome appearing more frequently in adults over fifty years of age. Hearing aids cannot completely correct this discrimination problem and, therefore, the aging individual must rely more and more on the visual channel for communication.

Thus, for the older hearing impaired person with phonemic regression, the skill of speechreading would become essential to their continued social and emotional well being. Knowledge of those factors which directly affect the older person's ability to learn speechreading will provide basic information necessary for design- 
ing individualized programs.

Memory appears to be an area which is important to learning the skill of speechreading. While learning and memory are usually differentiated, the measuring methods are similar for both. Learning is measured as a change in performance after practice or experience, while memory is measured by how well the learned material is retained after some specified length of time. In a sense, the measurement of learning may be referred to as immediate or short term memory. The speechreading task is considered to involve the ability to hold in short term memory a visual image until enough information is provided for decoding the speaker's message. O'Neill and Oyer (1961) have emphasized the importance of visual short term memory to speechreading ability. Jeffers and Barley (1971) estimated the contribution of visual short term memory to speechreading ability to be "from 18 to 35 percent," based on the results of eleven studies.

Studies involving short term memory tasks have documented a decline in performance with increased chronological age (Botwinick, 1973; Craik, 1968; Talland, 1968). If a relationship does exist between visual short term memory and speechreading ability, then the older individual would be expected to demonstrate greater difficulty in acquiring the skills necessary for good speechreading performance. Thus, visual short term memory should prove to be a critical factor to consider when planning a speechreading program for elderly clients.

\section{VISUAL SHORT TERM MEMORY AND SPEECHREADING}

The ambiguity of the term "visual short term memory" requires some clarifica- 
tion. Using a modification of the definition for short term memory provided by Botwinick (1973) visual short term memory is defined as retention for visually presented stimuli, covering a period of less than a second to minutes. This visual short term memory is subject to decay and/or interference.

A search of the literature failed to reveal a single study investigating short term visual memory and speechreading ability in older (over sixty years) hearing impaired people. The closest example to be found was a study by Simmons (1959) with hearing impaired adults, mean age forty-seven years. She compared the results of three speechreading tests (Utley, 1946; Mason, 1943; and an interview test constructed by the author) with scores from two measures of visual memory (Object Span Test and Digit Span Test). Significant correlations were found between the Object Span and all measures of speechreading. The Digit Span did not correlate with any of the speechreading tests.

O'Neill and Davidson (1956) also failed to find a relationshipbetween speechreading ability and visual memory for digits. Conversely, Costello (1957) obtained a significant positive correlation between speechreading and visual memory for digits in deaf and hard-of-hearing children. There are two plausible explanations for the discrepancies found by these investigators.

The first is related to the lack of a consistent and valid measure of speechreading ability. As previously mentioned (p.2) there are no standardized speechreading tests avai lable and the validity of the existing tests is questionable. DiCarlo and Kataja (1951) described the Utley Test (Utley, 1946) as a test of "ability to tolerate frustration and persistent failure in addition to testing speechreading 
ability." Since many of the speechreading tests base their validity on the Utley Test, they do not differ significantly in how or what they test.

The second possibility involves the validity of using visually presented digits as a measure of short term memory. The only standardized Digit Span Tests were designed to be presented auditorially, i.e., Wechsler Intelligence Scale. It cannot be assumed that an individual will perform equally when the digits are presented visually. In addition, digit span has been shown to be an unreliable indicator of short term memory deficits. Craik (1968) designed an experiment to test memory span in young and old subjects using words and digits. The older subjects recall of digits did not differ significantly from the young while their folder subjects) performance on the word recall task was poorer. He reasoned that little search is required for digits and therefore the task was not sufficiently difficult to differentiate between good and poor short term memory. Similar results have been reported by Aten and Davis (1968) with learning disabled children, and Rapaport et al. (1968) in patients with known brain pathology.

The effects of visual memory practice on speechreading ability has been studied by Mahaffy (1964). He used a tachistoscope to determine if visual memory practice would improve speechreading ability as measured by a filmed speechreading test . His subjects were normal hearing students. The experimental groups, those who received visual memory training, showed improvement in speechreading over the control groups after brief periods of training.

O'Neill and Oyer (1961) also stressed the importance of training visual memory to improve speechreading skill. They suggested using abstract figures, embed- 
ded figures and truncated words as stimulus materials.

While there is a lack of evidence to support the theory of a relationship between short term visual memory and speechreading ability, a great deal of research has been done in the area of short term memory and aging. Some of these studies provide information relevant to the investigation of speechreading abilities in older people.

\section{SHORT TERM MEMORY AND AGING}

Short term memory can be discussed in terms of both recall and recognition processes. Recall memory involves storage and retrieval whereas recognition memory requires only storage (Botwinick, 1973). Both require registration of the sensory data. McNulty and Caird (1966) believed recall to require total learning while in recognition memory only partial learning is necessary.

An examination of the speechreading task suggests that both processes may be required for attaining good speechreading skills. The proficient speechreader must have adequate stored knowledge concerning speech and language. When the message is unfamiliar or requires fine discrimination, such as with homophenous sounds and words, the task involves recall memory, i.e., a search for retrieval of stored information out of a large group of possibilities. Overlearned speech (familiar phrases heard and seen daily) would appear to require recognition memory. The speechreader only needs to hear or see part of the message for comprehension because of its highly familiar nature and small group of possible choices.

Iversen (1973) has proposed a model of memory which illustrates how these 
two memory processes may work (Figure 2). She suggests that,

Short term memory ... process is only brought into action if the quality, quantity, organization, or temporal characteristics of the incoming information overloads the direct route from input to permanent storage. In this way, some very simple immediate memory tests or subspan memory tests which involve uncomplicated registration and immediate retrieval, may not involve short term memory processes ... but only the immediate memory with its independent access to long term stores... digit span in the verbal or nonverbal mode is an excellent example.

According to her theory, a distuption of immediate memory would involve massive cerebral damage while short term memory deficits would be evident after discrete brain lesions.

Up to this point, short term memory has been discussed without differentiating between auditory and visual stimuli. In all age groups, auditory memory is superior to visual memory for the same material (Buschke, 1962; Glanzer, 1977). Reportedly, there is a greater decline with age in visual short term memory than in auditory short term memory (Klonoff and Kennedy, 1965; McGhie et al., 1965). Typically the hard of hearing adult relies on both auditory and visual cues for communication (Erber, 1975). It is not unreasonable to assume that there is some interaction between the visual and auditory reception, i.e., a translating of the visual into a verbal message. Baddeley and Hitch (1977) have suggested a "common central processor" for the two modes. For the older speechreader the necessity of relying on visual information which must be recoded into auditory form may lead to an overloading of an al ready limited capacity storage. Drachman and Leavitt (1972), and McNulty and Caird (1966) suggested a storage deficit as an explanation for short term memory deficits in the aged.

Other investigators have shown age deficits in registration and retrieval of 


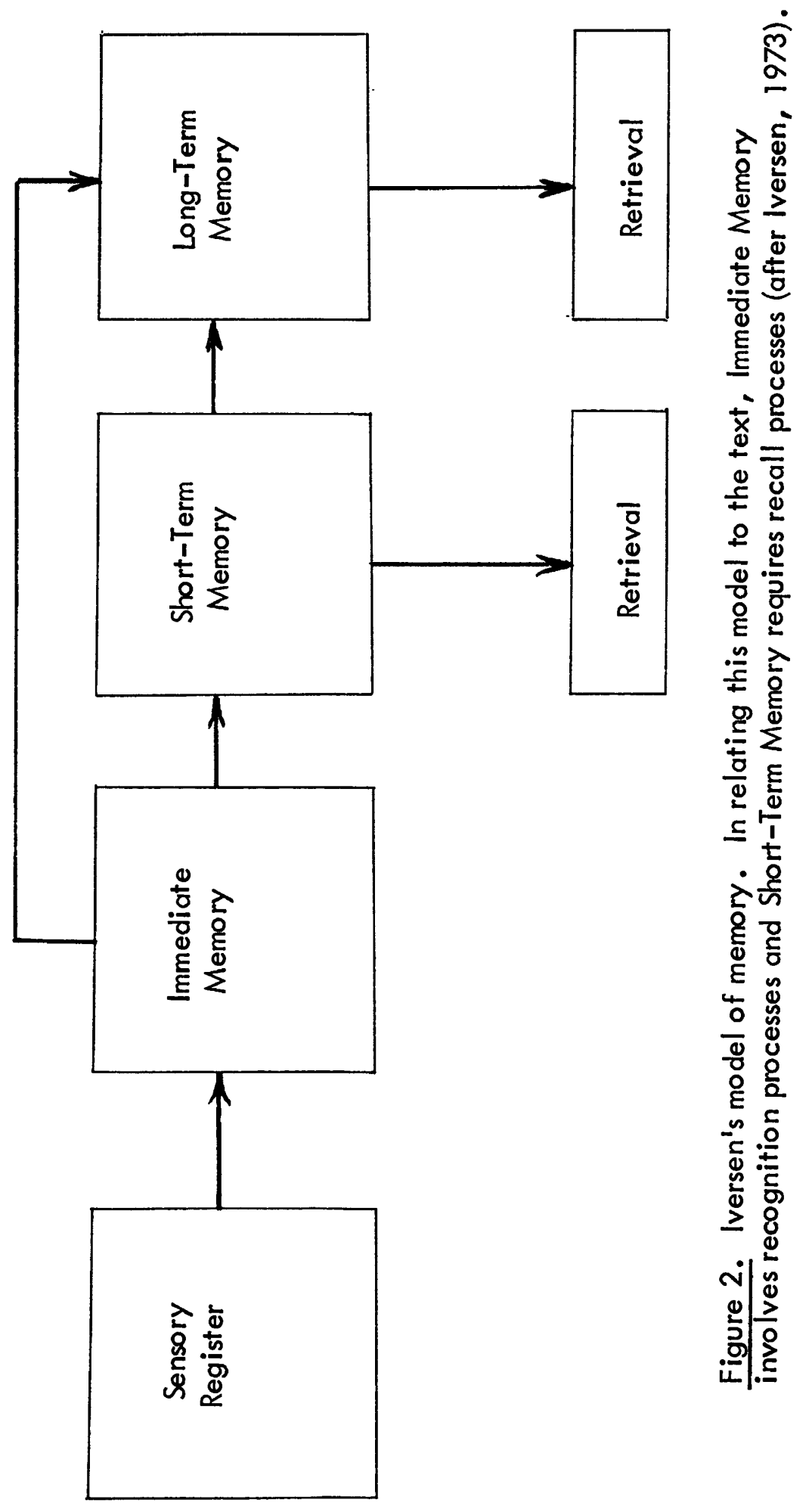


stored information. Of particular interest to this study of speechreading are the effects of stimulus duration and rate of presentation on short term memory in older people. The use of stimulus persistence as a direct measure of short term visual storage has been advocated by Haber and Standing (1969). Eriksen et al. (1970) reported older adults require longer stimulus duration for identifying forms, reflecting a general slowing in processing. Kline and Orme-Rogers (1978) found older subjects performance superior to younger subjects when the inter-stimulus-interval and duration were increased.

A study by Adamowicz (1976) tested visual short term memory functioning in young and old adults using recall and recognition tasks. The stimuli consisted of simple and complex visual patterns. He found age related decrements in visual short term memory for recall tasks if the stimulus duration time was too short. Decrements were also found for recognition tasks but not as great. The author interpreted these findings as suggestive of slower information processing at the registration stage and a greater susceptibility to interference in the aged. That is, age related deficits were noted at the encoding and post-encoding but not the retrieval stage. Arenberg (1968) has suggested that fast pacing maximizes interference among the aged. In the initial learning of a task, the pace should be slowed.

Several investigators have found that recall of visual stimuli increases as rate decreases (Monty et al ., 1965; Posner, 1963). Taub (1966) studied rate of visual presentation as a function of age using a series of nine letters in a random sequence. Results indicated aged subjects retained fewer letters than young subjects, and both recalled more when the rate of presentation was decreased. According to 
Taub, the slower rate allowed for rehearsal and less interference by previously stored information in the older subjects. The presentation rates of one second per letter and two seconds per letter were considerably slower than the rate of ordinary conversation, averaging approximately thirteen articulatory movements per second (Stevens, 1960). Assuming that in the speechreading task, the visual image is also subject to interference, learning may be more difficult for the aged when the material is presented at normal speech rate.

Another area of interest to speechreading involves the effects of auditory augmentation on visual short term memory. In a series of experiments, Arenberg $(1968,1976)$ presented visual stimuli (digits and words) to young and old subjects under three conditions: (1) visual only; (2) active-auditory (subject said stimulus aloud); and (3) passive auditory (experimenter said stimulus aloud).

Results revealed that active and passive auditory augmentation enhanced short term memory in recall of most recently presented items (digits and words) for both groups. Recall of last items is comparable to immediate memory processes. For items at the beginning of a list, the visual only condition resulted in better recall with the active-auditory producing the poorest recall. The young group recalled more under all conditions and the effect of input conditions was significant only for the older group.

Active auditory augmentation is a strategy often used in speechreading classes, the purposebeing to get the "feeling" (muscular sensations and rhythm) of speech. Arenberg believed vocalization may have resulted in some type of memory load for the older group, preventing recall of earlier items. Since recall of items at 
the beginning is more comparable to applied learning, he suggested the older learner should avoid active-auditory augmentation in learning situations.

In a more recent study, Arenberg (1977) used designs from the Benton Visual Retention Test presented with and without auditory descriptions. Auditory cues improved retention for the old group (experimental group) over the control group (no cues). The young group performed better, committing fewer errors under either condition but this was attributed to a ceiling effect. Arenberg interpreted the findings in favor of active rehearsal by the examiner to enhance storage and retrieval of information in the aged.

An aspect of short term memory research which does not involve visual imagery but is related to speechreading, concerns the finding of less efficient use of linguistic redundancy in the old. The redundancy of our language allows the speechreader to interpret the message with parts missing or to fill in the missing symbols by guessing.

Craik (1968) tested whether old people recognized redundancy in English text as efficiently as the young. Subjects were required to guess each successive letter in a simple sentence. The results indicated older subjects took significantly longer to guess the letters and required more guesses to complete the sentence. Craik suggested these results might indicate older people have forgotten the probability structure of English, resulting in deficits in registration. An alternative explanation concerned the possibility of a retrieval deficit which again involves recall memory.

The age related deficits in short term memory lead to speculation as to how 
the older person's ability to learn speechreading might be affected. Older people have been characterized as slower, less efficient learners. Simmons (1959) found older subjects acquired the skill of speechreading more slowly than younger subjects. However, there is a great range of individual differences in ability to learn a new task among the chronologically aging, just as there is in the young. In fact, this range may be even larger for the old than for the young. As reported by Botwinick and Thompson (1968), some older people perform more quickly than the young. It has been shown that experience and practice minimize age-related slowness (Murrell, 1970).

The age related decrement in performance speed has been associated with changes in the central nervous system (Botwinick, 1973). Warrington and Rabin (1971) tentatively identified the left posterior portion of the hemisphere as the site of lesion for visual short term memory deficits. Specifically, patients with left parietal, occipital, or parieto-temporal lesions performed significantly poorer on visual short term memory tasks than patients with right hemisphere or non posterior damage. Speechreading requires combined visual perception (occipital lobe) and auditory perception (temporal lobe) and also language comprehension (posterior temporoparietal area). Therefore, minimal damage to any of these areas, as evidenced by slowness or poor short term memory, may affect the person's ability to acquire speechreading skills. A study by Shepherd et al. (1978) found a significant relationship between visual-neural firing time and speechreading scores. They proposed that "subjects with faster firing neurons may transmit information more rapidly for central processing, such as visual short term memory." 
It appears that the presbycusic with poor short term visual memory presents distinct learning problems. These problems need to be solved if the older population is to ever acquire adequate speechreading skills. This study takes a first step by investigating the relationship between visual short term memory and speechreading ability in hearing impaired geriatrics. 


\section{CHAPTER III}

\section{METHOD}

\section{SUBJECTS}

Subjects for this study were recruited from various senior centers throughout the Portland and surrounding areas. The sample population consisted of thirteen females and fourteen males for a total of twenty-seven subjects. All subjects were sixty years of age or older, range sixty to eighty-six, and mean age of seventythree and one half (73.5). Each subject reported a gradual loss of hearing and exhibited a bilateral, sloping sensori-neural type hearing impairment. Twenty subjects averaged $35 \mathrm{~dB} \mathrm{HL}$ (American National Standards Institute, ANSI S3.61969,1970 ) or greater loss in the better ear for the frequencies 500; 1000 and 2000 $\mathrm{Hz}$. The remaining seven subjects had high frequency losses which did not affect the low and mid frequencies to any significant degree. All subjects reported some difficulty in hearing.

In addition, subjects were required to meet the following criteria: (1) normal or corrected visual acuity or 20/30 or better in both eyes as determined by the Snellen Chart; (2) at least a high school education or equivalent; (3) generally good mental and physical health as reported by the subject; and (4) no prior formal training in speechreading or visual memory tasks. 


\section{INSTRUMENTATION}

A Beltone portable audiometer was used to conduct the initial pure tone threshold testing. A Maico 24B audiometer was used to perform the audiologic assessments. Calibration checks were conducted prior to testing to assure appropriate air conduction, bone conduction, and speech references (ANSI, 1969).

The Memory for Designs Test (MFD) by Graham and Kendall $(1946,1947)$ was developed for possible use as a diagnostic instrument for the identification of organic cerebral pathology. Individuals with organic brain syndromes often display impaiment in memory for recent events (Coleman, 1972). The test requires presentation of simple geometric designs and the reproduction of these designs from memory. Graham and Kendall (1960) pointed out that the task also requires attending, perceiving and motor action and, therefore, is not a pure measure of short term memory. However, with the exception of the first two figures, the designs are relatively free of meaningful association and, on the basis of face validity, the MFD test appears to be an adequate measure for assessing recall processes of visual short term memory (Figure 3 ).

Graham and Kendall (1960) reported reliability correlations of .99 for independent ratings of total scores. The index of reliability using a split-half method was reported to be .92 for the original population of 140 subjects, indicating good internal consistency. Test-retest reliabilities ranged from .72 to .90 , indicating some practice effect. The MFD test has the advantage of being standardized on groups over sixty years of age (Kendall, 1962). The means of raw scores for various age groups are shown in Table 1. 

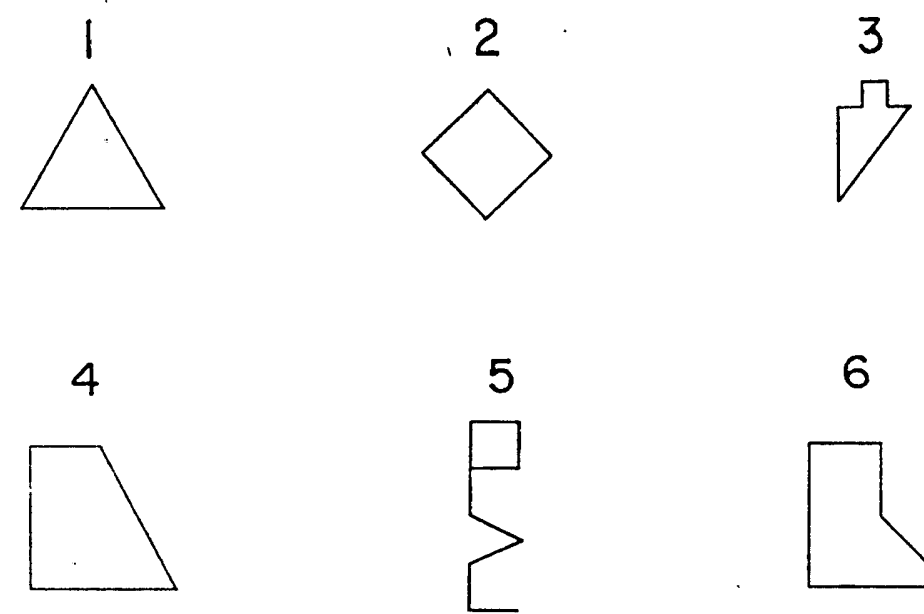

6
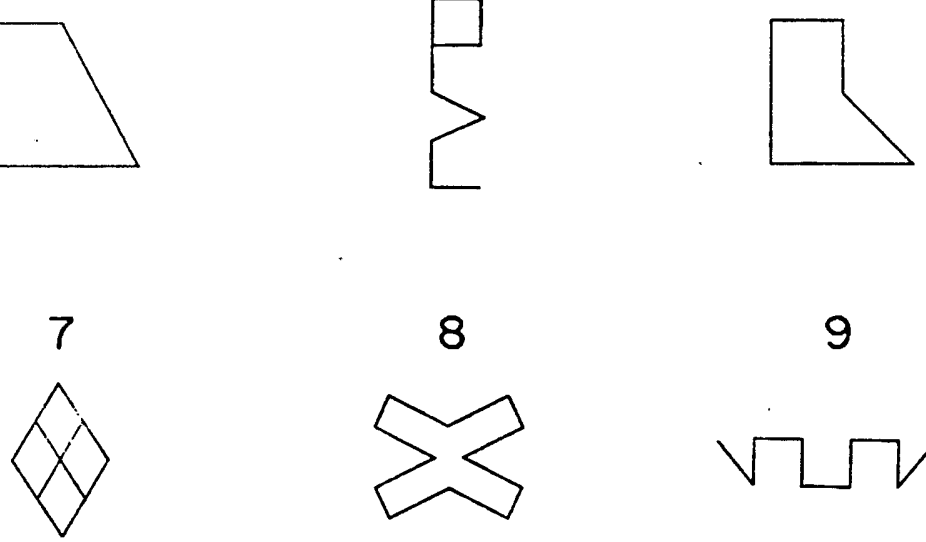

8

9<smiles>CCCCC12CCCCC1CCCC2</smiles>
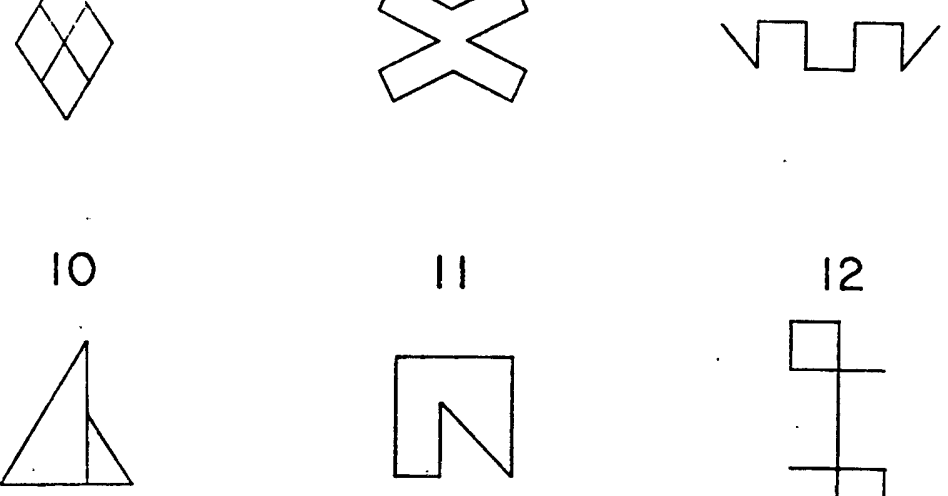

11

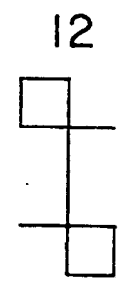

13

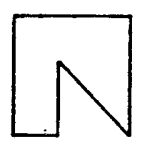

15

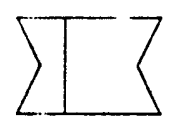

14

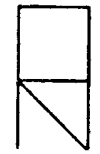

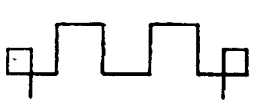

Figure 3. Designs from Memory for Designs Test (from Graham and Kendall, 1960). 


\section{TABLE I}

MEANS OF RAW SCORES FOR VARIOUS AGE RANGES OF THE 1960 DATA AND OVER 60 CONTROL SAMPLES FOR THE MFD TEST $(\mathrm{N}=373)$

\begin{tabular}{crcc}
\hline Age Range & $N$ & Mean & SD \\
\hline & & & \\
$71-80$ & 6 & 8.33 & 4.85 \\
$61-70$ & 30 & 8.47 & 6.58 \\
$51-60$ & 31 & 4.03 & 4.07 \\
$41-50$ & 58 & 4.29 & 5.12 \\
$31-40$ & 94 & 3.24 & 3.49 \\
$21-30$ & 104 & 2.87 & 4.70 \\
$16-20$ & 50 & 2.04 & 2.96 \\
\hline
\end{tabular}

From Kendall, 1962.

The Barley Speechreading Test-CID Everyday Sentences (Jeffers and Barley, 1971 ) was designed to assess speechreading ability of both children and adults. The test consists of two equivalent forms $(r=.87)$ of twenty-two sentences each. The Utley Sentence Test (Utley, 1946) was used as the criterion for validation with a reported coefficient of correlation of .79 between Form A of the Barley and Form A of the Utley. The author claims high face validity based on the content of everyday colloquial speech.

Form A of the Barley Speechreading Test was presented by the examiner and recorded, without sound, on one-half inch Memorex EIAJ open reel video tape using a Sony 8650 video tape recorder. Each sentence was recorded once at a rate below average conversational speech but within the normal range to avoid exaggeration and distortion of the message. The test was displayed on a Carlson Video Tape player with ample time allowed between sentences to permit the sub- 
jects to write a response.

\section{PROCEDURES}

An initial pure tone, air conduction threshold test was administered to some subjects at $500,1000,2000,3000$, and $4000 \mathrm{~Hz}$. Subjects with a hearing loss at any of these frequencies were asked to participate in the study. All subjects were sixty years of age or older at the time of the initial testing.

All subjects received a complete audiologic assessment, consisting of pure tone, air and bone conduction testing, speech reception threshold, most comfortable listening level $(M C L)$, uncomfortable level $(U C L)$, speech discrimination testing and performance intensity function presented $5 \mathrm{~dB}$ below $\mathrm{UCL}$.

Subjects received a visual acuity screening prior to taking the speechreading test. The Barley Speechreading Test-CID Everyday Sentences was administered to no more than two subjects at the same time. Subjects were seated approximately six feet from the screen with adequate lighting provided for writing responses. Subjects were instructed to write whatever they thought the speaker said and to guess if they were not sure. Ample time was allowed for responding. The score obtained was based on the number of words correctly perceived and recorded. The total possible score was 125 words correct.

The Memory for Designs test was administered to each subject individually in a quiet room with no observers present. Each subject was provided with a pencil and paper. The following instructions were given: 
I am going to show you some cards with drawings on them. I will let you look at a card for five seconds; then I will take it away and let you draw from memory what you have seen. Be sure to look at the drawings carefully so you can make yours just like it. Don't start to draw until I take the card away (Graham and Kendall, 1960).

The examiner questioned each subject to determine that the instructions had been heardand understood. Each card was presented for five seconds and then removed. No attempt was made to urge guessing or completion of partly remembered designs.

The subjects designs were evaluated independently by the examiner and one other person. Each design was scored on a four point scale with values from $0-3$ as outlined in the revised manual (Graham and Kendall, 1960). Points are given for errors, therefore, higher scores indicate poorer performance on the visual memory task. There was no penality for lack of artistic ability. The total possible score was 45 errors. 


\section{CHAPTER IV}

\section{PRESENTATION OF RESULTS}

The data obtained in this study were compared to the normative data reported for the Barley Speechreading Test (Jeffers and Barley, 1971) and the Memory for Designs Test (Kendall, 1962). The means, standard deviations and ranges achieved by the twenty-seven subjects in this study are shown in Table II (speechreading) and Table III (visual short term memory) along with the norms. The norms reported in Table III for the MFD test are for the sixty-one to seventy year age group only because of the larger population. However, normative data reported for the seventy-one to eighty year age group did not differ significantly (see Table I).

\section{TABLE ॥}

COMPARISON OF DATA OBTAINED IN THIS STUDY WITH NORMATIVE DATA REPORTED FOR THE BARLEY SPEECHREADING TEST

\begin{tabular}{lcc}
\hline \hline Measures & $\begin{array}{c}\text { Experimental Subjects } \\
\mathrm{N}=27\end{array}$ & $\begin{array}{c}\text { Barley Subjects } \\
\mathrm{N}=92\end{array}$ \\
\hline & & \\
Mean & 15.63 & 59.20 \\
SD & 13.00 & 25.40 \\
Range (correct word scores) & $2-65$ & $14-109$ \\
\hline
\end{tabular}

The Barley norms for the mean number of words correctly identified exceeded scores obtained by the experimental population by approximately forty-four words. 
In contrast, the subjects in this study made approximately three less errors than a similar chronological age group reported by Kendall (1962) for the MFD.

\section{TABLE III}

COMPARISON OF DATA OBTAINED IN THIS STUDY WITH NORMATIVE DATA REPORTED FOR THE MEMORY FOR DESIGNS TEST

\begin{tabular}{lcc}
\hline \hline Measures & $\begin{array}{c}\text { Experimental Subjects } \\
N=27\end{array}$ & $\begin{array}{c}\text { MFD (61-70 Age Group) } \\
\mathrm{N}=30\end{array}$ \\
\hline & & \\
Mean & 5.33 & 8.47 \\
SD & 4.20 & 6.58 \\
Range of Error scores & $0-16$ & $0-25$ \\
\hline
\end{tabular}

The raw scores (error scores) achieved by the twenty-seven subjects in this study on the Barley Speechreading Test and the Memory for Designs Test were converted to standard scores ( $z$ scores) to facilitate correlation between tests of different length and nature (Mendenhall, 1971). The correlation was calculated between $z$ scores obtained on the MFD test and $z$ scores for the Barley Speechreading Test. The resultant correlation coefficient of .58 was statistically significant from zero $(\rho<.005)$ to indicate a substantial relationship between speechreading scores and visual short term memory scores.

Since the correlation between tests is always reduced or attenuated if either test is unreliable, a correction can be made which will estimate the correlation between two tests taking into account errors of measurement or chance errors (Garrett and Woodworth, 1966). The corrected correlation coefficient, based on the reported reliabilities of the Barley Speechreading Test (Jeffers and Barley, 
1971 ) and the Memory for Designs Test (Graham and Kendall, 1960), was .73. The corrected correlation represents the theoretical upper limit which could be obtained between speechreading scores and short term visual memory scores if the two sets of obtained scores for the tests used in this study were perfect measures. Due to chance errors, the obtained $r$ is always less than the corrected value and may be regarded as a minimum index of the relationship present.

The correlation between two variables is often influenced by a third or more variables. While this study attempted to control obvious variables which could influence performance on short term visual memory and speechreading tasks, a difference was noted between the scores obtained for the subjects in the sixth and seventh decades of life (Table IV). Analysis of the results by decades suggested chronological age may have influenced the relationship found between the Barley Speechreading scores and MFD scores. Another variable of interest was speech discrimination ability. Since the speechreader may be required to translate a visual into a verbal message, auditory discrimination ability could contribute to the variance found in the speechreading scores.

By means of partial correlation, variability contributed by chronological age differences and speech discrimination ability were held constant, leaving the net correlation between speechreading and visual short term memory scores. The results of the correlations are given in Table $V$. The resultant partial correlation of .56 $(p<.005)$ indicates that the relationship found in this study between scores achieved on the Barley Speechreading Test and the MFD test were not influenced significantly by variance in chronological age or speech discrimination ability. 
TABLE IV

COMPARISON OF RESULTS FROM THE BARLEY SPEECHREADING TEST (SR) AND THE MEMORY FOR DESIGNS TEST (MFD) BY DECADES.

RESULTS FOR ALL AGES COMBINED

ARE ALSO GIVEN.

\begin{tabular}{lrcrrrrr}
\hline \hline \multicolumn{7}{c}{ Mean Errors } & \multicolumn{2}{c}{ SD's } & & \\
Age & $N$ & Barley SR & MFD & Barley SR & MFD & r's & Significance \\
\hline & & & & & & & \\
$60-69$ & 7 & 102.14 & 1.29 & 19.58 & 1.6 & .37 & NS \\
$70-79$ & 15 & 112.33 & 6.73 & 8.60 & 4.0 & .70 & .01 \\
$80-89$ & 5 & 110.60 & 6.80 & 7.60 & 3.3 & .61 & NS \\
All & 27 & 109.37 & 5.33 & 13.00 & 4.2 & .58 & .005 \\
\hline
\end{tabular}

\section{TABLE V}

ORIGINAL AND PARTIAL CORRELATIONS BETWEEN (1) BARLEY SPEECHREADING SCORES, (2) MEMORY FOR DESIGNS SCORES, (3) AGE, AND (4) SPEECH DISCRIMINATION SCORES IN THE BETTER

EAR AT MCL. THE SUBSCRIPTS 12.34 MEAN THAT

VARIABLES 3 AND 4 ARE HELD CONSTANT

LEAVING THE NET CORRELATION

BETWEEN 1 AND 2.

\begin{tabular}{cl}
\hline Original Correlation & Partial Correlation \\
\hline & \\
$r_{12}=.58^{*}$ & $r_{1235}=.56^{*}$ \\
$r_{13}=.45^{*}$ & $r_{13,24}=.41^{*}$ \\
$r_{23}=.22$ & $r_{2394}=-.06$ \\
$r_{14}=.37^{*}$ & $r_{1423}=.30$ \\
$r_{24}=.22$ & $r_{24,3}=.03$ \\
\hline
\end{tabular}

* Significant at .05 level

The proportion of variance found in speechreading scores which is attributable to the jointaction of visual short term memory, age and speech discrimination was 
calculated to be $54 \%$ (Table V1). That is, $54 \%$ of whatever caused the subjects in this study to differ on the Barley Speechreading Test can be attributed to differences in visual short term memory (as measured by the MFD), chronological age and speech discrimination ability. The total percentage can be broken down further into the contribution of visual short term memory $(30 \%)$, age $(15 \%)$, and speech discrimination ability (9\%). The remaining $46 \%$ of the variance found in the speechreading performance of older subjects must be attributed to factors not measured in this study.

\section{TABLE VI}

PERCENTAGE OF VARIANCE FOUND IN SPEECHREADING ATTRIBUTED TO FACTORS OF VISUAL SHORT TERM MEMORY, AGE AND SPEECH DISCRIMINATION ABILITY

\begin{tabular}{lc}
\hline \multicolumn{1}{c}{ Factors } & Variance (\%) \\
\hline & \\
Short Term Visual Memory (MFD) & .30 \\
Age & .15 \\
Speech Discrimination Ability & .09 \\
Unknown Factors & .46 \\
\hline
\end{tabular}

Visual short term memory was the only factor which showed a substantial correlation with speechreading $(r=.56)$ and thus accounted for $30 \%$ of the variance. The usefulness of the MFD test for predicting performance on the Barley Speechreading Test was evaluated by means of a regression equation (Garrett and Woodworth, 1966). A tabular description of the predicted and obtained speechreading scores for the twenty-seven subjects in this study are shown in Table VII. The standard error of estimate in predicting a speechreading score from a MFD score was 
calculated to be 10.53 words. This may be interpreted to mean that for a group of elderly, beginning speechreaders, the chances are about two in three (68 in 100) that a speechreading score predicted from a MFD score will not miss the score actually achieved on the Barley Speechreading Test by more than ten to eleven words.

\section{TABLE VII}

COMPARISON OF THE SCORES ACHIEVED BY THE TWENTY-SEVEN SUBJECTS ON THE BARLEY SPEECHREADING TEST WITH PREDICTED SCORES DERIVED FROM THE REGRESSION EQUATION, $\bar{X}=r \frac{\sigma_{x}}{\partial y}(Y-M y)+M x$,

WHERE $\bar{X}=$ PREDICTED BARLEY SPEECHREADING SCORE, $Y=$ MFD SCORE, $M X=$ MEAN ERRORS ON BARLEY SPEECHREADING TEST, MY = MEAN ERRORS

ON MFD TEST. THE STANDARD ERROR OF ESTIMATE $=10.53$ WORDS.

\begin{tabular}{cccc}
\hline \hline N & MFD scores & $\begin{array}{c}\text { Predicted } \\
\text { Barley scores }\end{array}$ & $\begin{array}{c}\text { Obtained } \\
\text { Barley scores }\end{array}$ \\
\hline & & & \\
4 & 0 & 99.25 & 98.25 \\
2 & 1 & 101.20 & 99.50 \\
3 & 2 & 103.15 & 108.00 \\
2 & 3 & 105.10 & 99.00 \\
2 & 4 & 107.05 & 102.00 \\
1 & 5 & 109.00 & 114.00 \\
3 & 6 & 110.96 & 116.00 \\
1 & 7 & 112.90 & 121.00 \\
3 & 8 & 114.85 & 115.33 \\
2 & 9 & 116.80 & 118.00 \\
2 & 11 & 120.70 & 115.00 \\
1 & 12 & 123.65 & 116.00 \\
1 & 16 & 130.45 & 123.00 \\
\hline
\end{tabular}

To test the validity of the correlation between Barley Speechreading scores and MFD scores, the speechreading ability of three older hearing impaired subjects 
not included in this study, was predicted from their MFD scores and compared to their achieved scores. The results are shown in Table VIII.

\section{TABLE VIII}

BARLEY SPEECHREADING ERROR SCORES ACHIEVED BY THREE SUBJECTS COMPARED TO THE PREDICTED SCORES TAKEN FROM TABLE VII

\begin{tabular}{lccc}
\hline \hline Subject & MFD scores & $\begin{array}{c}\text { Obtained } \\
\text { Barley scores }\end{array}$ & $\begin{array}{c}\text { Predicted } \\
\text { Barley scores }\end{array}$ \\
\hline & & & \\
1 & 7 & 109 & 112.90 \\
2 & 0 & 94 & 99.25 \\
3 & 1 & 91 & 101.20 \\
Means & 98 & 104.45 \\
Difference between means & & 6.45 & \\
\hline
\end{tabular}

The mean predicted error score $(N=7)$ was 104.45 errors and the mean measured speechreading score $(\mathrm{N}=3)$ was 98 errors. The difference between the means was nonsignificant $(t=.26 ; \mathrm{df}=8 ; \rho>.05)$.

\section{DISCUSSION}

The primary purpose of this study was to explore the relationship between speechreading ability and short term visual memory in hearing impairedgeriatrics. Results of the study indicate that visual short term memory (as measured by the MFD) is an important factor to consider when assessing the older hearing impaired person's ability to speechread. Subjects with better MFD scores generally performed better on the Barley Speechreading Test than subjects with poor MFD scores. 
The chronological age variance of the subjects used in this study did not significantly affect the relationship between speechreading scores and short term visual memory scores. In fact, the finding of zero order partial correlation (see Table $V)$ between MFD scores and age, when speechreading scores were held constant, suggests variance in speechreading ability influenced the relationship between age and MFD scores. Had every subject in the group earned the same score on the Barley Speechreading Test, the correlation between visual short term memory scores and age would have been much lower than was noted for this sample which varied widely in speechreading ability.

It was observed that the sample used in this study performed considerably poorer on the Barley Speechreading Test than the normative population. However, Barley (Jeffers and Barley, 1971) reported the normative data were obtained from subjects enrolled in speechreading classes, while subjects used in the present study had never been formally exposed to speechreading in any manner. Four subjects were not used in this study because they were enrolled in a speechreading class and had attended one session. Their mean score was 32.75 words correct, compared to the mean of 15.63 words correct achieved by the experimental population. It was noted that those enrolled in speechreading classes appeared to be motivated to try harder and tended to make more guesses. Since the test is scoreed according to the number of words correctly identified, and most of the words are found in common everyday speech, those people who made more guesses tended to achieve a higher score.

Other possible explanations for the observed differences include, speaker 
variability and chronological age differences. Barley did not report ages, only that the "experimental population consisted of five adult speechreading classes (Jeffers and Barley, 1971)."

The opposite trend was noted for MFD scores. Approximately half $(N=13)$ of the subjects in this study achieved a score of four errors or less compared to the mean error score of eight reported by Kendall (1962) for a similar chronological age group. However, among the normative population of controls over age sixty, two-thirds had been diagnosed as psychotic and three of the subjects had not gone beyond the third grade (Kendall, 1962). The subjects in the present investigation all reported good mental health and all had at least a high school education or the equivalent. It is believed that the scores achieved on the MFD by subjects in this study are more representative of a "normal" population of persons age sixty and older than the Kendall norms.

The most interesting and possibly most important knowledge acquired from this study was the possible use of the MFD test for predicting speechreading ability (as measured by the Barley Speechreading Test). Considering the problems inherent to the present speechreading tests (see Chapter II), almost any alternative would be welcome.

The first advantage of the MFD over the Barley Speechreading Test, is time. The average administration time for the Barley test was twelve minutes, while the average time required to complete the MFD was five minutes. The MFD is also easier to administer and is not as likely to be influenced by examiner variability.

But the greatest advantage was the subjects reactions to taking the MFD as 
opposed to the Barley Speechreading Test. The Barley test was so difficult subjects became frustrated and would have given up if the examiner had not encouraged continuation. Two subjects were dropped from the study because they refused to even try. Subjects who completed the test (observed all twenty-two sentences) expressed feelings of embarrassment at having failed the test. In contrast, few subjects displayed signs of anxiety or frustration while responding to the MFD test and none commented on the difficulty of the task.

From the results, it appears that a more logical approach to evaluating a person's speechreading ability would be to design a test composed of factors (i.e., visual short term memory) which contribute to speechreading ability. An individval's speechreading ability could be estimated and areas of weakness identified. The clinician could then work on strengthening the weaknesses and the client could avoid the frustration and humiliation of repeated failure. 


\section{CHAPTER V}

\section{SUMMARY AND IMPLICATIONS}

The purpose of this study was to determine if a significant relationship exists between visual short term memory and speechreading ability in older hearing impaired subjects. Twenty-seven hearing impaired persons, ranging in age from sixty years to eighty-six years, participated as subjects. All subjects were required to respond to the Barley Speechreading Test and the Memory for Designs Test.

As a result of the data collected in this study, it was concluded that:

(1) There is a significant relationship between visual short term memory and speechreading ability in older hearing impaired subjects. Older people with good visual short term memory tend to speechread better than older people with poor visual short term memory.

(2) Chronological age (within the range of this study) does not have a significant influence on the relationship between Barley Speechreading scores and Memory for Designs scores.

(3) Speech discrimination ability showed a low but significant relationship to speechreading scores. Older hearing impaired subjects who scored better on the Barley Speechreading Test tended to have better speech discrimination ability than those subjects with poor speechreading scores. Speech 
discrimination scores did not contribute to the relationship between Barley Speechreading scores and Memory for Designs scores.

(4) Visual short term memory (MFD) can be used to predict the speechreading scores (Barley Speechreading Test) of elderly, beginning speechreaders.

\section{IMPLICATIONS FOR FUTURE RESEARCH}

The rehabilitation problems of hearing impaired geriatrics need to be approached in a scientific rather than intuitive manner. This study illustrates how variables affecting speechreading ability can be identified. The next step would be to determine if the older hearing impaired subject's short term memory could be improved and, if so, would speechreading ability also improve.

Factors (established for a much larger population than used in this study) which estimate speechreading ability could be used to develop a standardized, reliable speechreading test. Such a speechreading test could appropriately be termed "diagnostic," in the sense that it would examine facts to determine causes which could be "treated" to improve the skill. The current approach to teaching speechreading treats all hearing impaired people similarly, without regard for individual strengths and weaknesses.

Along the same line, systematic investigation of variables which may influence the learning (speechreading) process for older people, might include: (1) effects of pace (i.e., should presentation and speaking rate be slowed for the aged student?); (2) the effects of active (client speaks aloud) rehearsal during presentation of material for practice; and (3) the use of voice or no voice by the clinician 
during speechreading practice. In addition, many of the procedures recommended in texts on speechreading, have not been scientifically evaluated for effectiveness in improving speechreading ability. This is particularly true for people over sixty with hearing impairment.

An interesting study would be to compare speechreading scores for a group of older people who had been instructed to "guess" (a response would be required for every presentation) with a group who had not received any encouragement to guess. Botwinick (1973) reported aged subjects tended to be more rigid, making sure they could answer a question correctly before responding. Perhaps training older people to be more flexible (take chances) would improve their ability to acquire speechreading skills.

The ideas listed here are by no means exhaustive but they do illustrate the paucity of scientific research in the field of geriatric aural rehabilitation. Further research in this field could produce significant changes and improvements for the benefit of the aurally handicapped senior citizen. 
Adamowicz, J. K. "Visual Short-Term Memory and Aging. "Journal of Gerontology, $31: 39-46,1976$.

American National Standards Institute, Specifications for Audiometers, ANSI S3.61969. New York: National Standards Institute, Inc., 1970.

Arenberg, D. "Input Modality in Short-Term Retention." Journal of Gerontology, 23: $462-65,1968$.

- "The Effects of Input Condition on Free Recall in Young and Old Adults." Journal of Gerontology, $31: 551-55,1976$.

. "The Effects of Auditory Augmentation on Visual Retention for Young and Old Adults." Journal of Gerontology, 32: 192-95, 1977.

Aten, J. and Davis, J. "Disturbances in the Perception of Auditory Sequence in Children with Minimal Brain Dysfunction." Journal of Speech and Hearing Research, 11:236-45, 1968.

Baddeley, A. D. and Hitch, G. "Working Memory." In Human Memory, Basic Processes, Edited by G. Bower, New York-London-San Francisco: Academic Press, 1977.

Berger, K. W. Speechreading, Principles and Methods. Baltimore, Maryland: National Educational Press, 1972.

Black, J. W., O'Reilly, P. P. and Peck, L. "Self-Administered Training in Lipreading." Journal of Speech and Hearing Disorders, 28: 183-86, 1963.

Bocca, E. "Clinical Aspects of Cortical Deafness." Laryngoscope, 68: 301-9, 1958.

Botwinick, J. Aging and Behavior. New York: Springer Publishing Company, Inc., 1973 .

Botwinick, J. and Thompson, L. W. "A Research Note on Individual Differences in Reaction Time in Relation to Age." Journal of Genetic Psychology, 112: $73-5,1968$. 
British Standard Institution, British Standard for the Normal Threshold of Hearing for Pure Tones by Earphone Listening, B.S. 2467. London: British Standard Institution, 1954.

Buschke, H. "Auditory and Visual Interaction in Immediate Memory." burnal of Psychiatric Research, 1:229-39, 1962.

Coleman, J. A., ed. Abnormal Psychology and Modern Life. 4th edition, pp. 517-59 Glenview, Illinois: Scott, Foresman \& Company, 1972.

Costello, M. R. "A Study of Speech Reading as a Developing Language Process in Deaf and Hard of Hearing Children." Ph.D. dissertation, Northwestern University, 1957.

Craik, F. "Short-Term Memory and the Aging Process." In Human Aging and Behavior, Edited by G. A. Talland, New York: Academic Press, 1968.

Davis, H. and Silverman, S. R. Hearing and Deafness. New York: Holt, Rinehart \& Winston, 1960.

Deland, F. Story of Lip Reading: Its Genesis and Development. Revised by Harriet Montague, Washington: The Volta Bureau, 1968.

Di Carlo, L. M. and Kataja, R. "An Analysis of the Utley Lipreading Test." Journal of Speech and Hearing Disorders, 16:226-40, 1951.

Drachman, D. A. and Leavitt, J. "Memory Impairment in the Aged: Storage versus Retrieval Deficit." Journal of Experimental Psychology, 93: 302-8, 1972.

Erber, N. P. "Auditory-Visual Perception of Speech." Journal of Speech and Hearing Disorders, 40: 481-92, 1975.

Eriksen, C. M., Hamlin, R. M. and Breițeyer, R. G. "Temporal Factors in Visual Perception as Related to Aging." Perception \& Psychophysics, 7: 354-56, 1970.

Gaeth, J. "A Study of Phonemic Regression in Relation to Hearing Loss." Ph. D. dissertation, Northwestern University, 1948.

Garrett, H. E. and Woodworth, R. S. Statistics in Psychology and Education. 6th edition, New York: David McKay Company, Inc., 1966.

Glanzer, M. "Storage Mechanisms in Recall." In Human Memory, Basic Processes, Edited by G. Bower, New York-London-San Francisoo: Academic Press, 1977.

Glorig, A. and Davis, H. "Age, Noise and Hearing Loss." Annals of Otology, Rhinology, and Larynogology, 70: 556-71, 1961. 
Goetzinger, C. P., Proud, G. O., Dirks, D. and Embrey, J. "A Study of Hearing in Advanced Age." Archives of Otolaryngology, 73: 662-74, 1961.

Graham, F. K. and Kendall, B. S. Memory for Designs Test. St. Lovis: Washington University, 1946.

Graham, F. K. and Kendall, B. S. "Note on the Scoring of the Memory for Designs Test." Journal of Abnormal and Social Psychology, 42: 253, 1947.

Graham, F. K. and Kendall, B. S. "Memory for Designs Test: Revised General Manual." Perceptual and Motor Skills, 11: 147-88, 1960.

Haber, R. N. and Standing, L. G. "Direct Measures of Short Term Visual Storage." Quarterly Journal of Experimental Psychology, 21 : 43-54, 1969.

Hansen, C. C. and Rieske-Nelson, E. "Pathological Studies in Presbycusis." Archives of Otolaryngology, 82: 115-32, 1965.

Hinchcliffe, R. "Correction of Pure Tone Audiograms for Advancing Ages." Journal of Larynogology, 73: 830-32, 1959.

1962

. "Aging and Sensory Thresholds." Journal of Gerontology, 17:45-50,

Hutton, C. "A Diagnostic Approach to Combined Techniques in Aural Rehabilitation." Journal of Speech and Hearing Disorders, 25: 267-72, 1960.

Iversen, S. D. "Brain Lesions and Memory in Animals." In The Physiological Basis of Memory, Edited by J. A. Deutsch, New York: Academic Press, 1973.

Jeffers, J. and Barley, M. Speechreading (Lipreading). Springfield, Illinois: Charles C. Thomas, 1971.

Johnsson, L. and Hawkins, J. "Sensory and Neural Degeneration with Aging, as Seen in Microdissections of the Human Ear." Annals of Otology, 81 : 17993, 1972 .

Kendall, B. S. "Memory for Designs in the Elderly." Perceptual and Motor Skills, 14: 399-405, 1962.

Kirikae, I., Sato, R. and Shitara, T. "A Study of Hearing in Advanced Age." Laryngoscope, 74: 205-20, 1964.

Kline, D. W. and Orme-Rogers, C. "Examination of Stimulus Persistence as the Basis for Superior Visual Indentification Performance Among Older Adults." Journal of Gerontology, 33: 76-81, 1978. 
Klonoff, H. and Kennedy, M. "Memory and Perceptual Function in Octogenarians and Nonagenarians in the Community." Journal of Gerontology, 20: 328$33,1965$.

Logan, $\dot{F}$. A. Learning and Motivation. pp. 2-7, Dubuque, lowa: William C. Brown Company Publishers, 1970 .

McGhie, A., Chapman, J. and Lawson, J. S. "Changes in Immediate Memory with Age." British Journal of Psychology, 56: 69-75, 1965.

McNulty, J. A. and Caird, W. K. "Memory Loss with Age: Retrieval or Storage?" Psychological Reports, 19: 229-30, 1966.

Mahaffey, R. B. "An Investigation Relating Short-Term Tachistoscopic Training to Improvement in Basic Speechreading Abilities." American Speech and Hearing Association, 6: 388, 1964.

Mason, M. K. "A Cinematographic Technique for Testing Visual Speech Comprehension." Journal of Speech and Hearing Disorders, 8: 271-78, 1943.

Mendenhall, W. Indroduction to Probability and Statistics. 3rd edition, Belmont, California: Duxbury Press, 1971.

Metropolitan Life, Statistical Bulletin. Vol. 57, pp. 7-9, Feb., 1976.

Monty, R. A., Taub, H. A. and Laughery, K. R. "Keeping Track of Sequential Events: Effects of Rate, Categories and Trial Length." Journal of Experimental Psychology, 69: 224-29, 1965.

Murrell, F. H. "The Effects of Extensive Practice on Age Differences in Reaction Time." Juurnal of Gerontology, 25: 268-74, 1970.

Myklebust, H. R. The Psychology of Deafness. New York: Grune and Stratton, Inc., 1960.

Nitchie, E. B. Lip-Reading, Principles and Practices. p. 341, Philadelphia and New York: Lippinoott, 1930.

O'Neill, J. J. and Davidson, J. L. "Relationship Between Lipreading Ability and Five Psychological Factors." Journal of Speech and Hearing Disorders, 21 : 478-81, 1956.

O'Neill, J. J. and Oyer, H. J. Visual Communication for the Hard of Hearing. Englewood Cliffs, New Jersey: Prentice-Hall, Inc., 1961.

Posner, M. I. "Immediate Memory in Sequential Tasks." Psychological Bulletin, 
$60: 333-49,1963$.

Rapaport, D., Gill, M. M. and Schafer, R. Diagnostic Psychological Testing. revised edition, pp. 71-160, New York: International University Press, 1968.

Sataloff, J, Vassalo, L. and Menduke, H. "Presbycusis, Air and Bone Conduction Thresholds." Laryngoscope, 75: 889-901, 1965.

Schuknecht, H. "Further Observations on the Pathology of Presbycusis." Archives of Otolaryngology, 80: 369-82, 1964.

Shepherd, D. C., DeLavergne, R. W., Frueh, F. X. and Clobridge, C. "VisualNeural Correlate of Speechreading Ability in Normal Hearing Adults."

Tampa, Florida: University of South Florida, 1978. (Mimeographed.)

Simmons, A. A. "Factors Related to Lipreading." Journal of Speech and Hearing Research, 2: 340-52, 1959.

Stevens, S. S., ed. Handbook of Experimental Psychology - p. 793, New York: John Wiley \& Sons, Inc., 1960.

Talland, G. A. "Age and the Span of Immediate Recall." In Human Aging and Behavior, Edited by G. A. Talland, New York: Academic Press, 1968.

Taub, H. A. "Visual Short-Term Memory as a Function of Age, Rate of Presentation, and Schedule of Presentation." Journal of Gerontology, $21: 388-94,1966$.

U. S. Bureau of the Census. Statistical Abstract of the U. S. 97th edition, Washington, D.C.: Government Printing Office, 1976.

Utley, J. "A Test of Lip Reading Ability." Journal of Speech and Hearing Disorders, $11: 109-16,1946$.

Vernon, M. and Mindel, E. D. "Psychological and Psychiatric Aspects of Profound Hearing Loss." In Audiological Assessment, Edited by D. E. Rose, Englewood Cliffs, New Jersey: Prentice-Hall, Inc., 1971.

Warrington, E. K. and Rabin, P. "Visual Span of Apprehension in Patients with Unilateral Cerebral Lesions." Quarterly Journal of Experimental Psychology, 23: 423-31, 1971 . 